\title{
Publisher Correction: Liquisolid Technique: a Novel Tool to Develop Aceclofenac-Loaded Eudragit L-100 and RS-100-Based Sustained Release Tablets
}

\author{
Yaseen Hussain $^{1,2}$ - Asim.ur. Rehman ${ }^{3}$ Muhammad Noor Shah ${ }^{4,5}$ \\ Published online: 21 September 2020 \\ (C) Springer Science+Business Media, LLC, part of Springer Nature 2020
}

Publisher Correction: Journal of Pharmaceutical Innovation https://doi.org/10.1007/s12247-020-09474-w

The original version of this article unfortunately contained a mistake. The authors in the author group were listed incorrectly. The correct author group of this article is "Yaseen Hussain - Asim.ur.Rehman • Muhammad Noor Shah."

The original article has been corrected.

Publisher's Note Springer Nature remains neutral with regard to jurisdictional claims in published maps and institutional affiliations.

The online version of the original article can be found at https://oi.org/ 10.1007/s12247-020-09474-w

Yaseen Hussain

20197250001@stu.suda.edu.cn; pharmycc@gmail.com

Asim.ur. Rehman

arehman@qau.edu.pk

Muhammad Noor Shah

nshahbpharm@gmail.com

1 Department of Pharmacy, Abdul Wali Khan University, Mardan, Khyber Pakhtunkhwa 23200, Pakistan

2 College of Pharmaceutical Sciences, Soochow University, Suzhou, People's Republic of China

3 Department of Pharmacy, Quaid-i-Azam University, Islamabad 45320, Pakistan

4 Department of Pharmacy, University of Swabi, Swabi, Khyber Pakhtunkhwa 23561, Pakistan

5 Navegal Laboratories, 41/1-A-2, Phase-1, Industrial Estate Hattar, Haripur, Khyber Pakhtunkhwa, Pakistan 